\title{
Antimicrobial enzymatic biofuel cells
}

\author{
Xiao, Xinxin; Ryan, Michael P; Leech, Dónal; Zhang, Jingdong; Magner, Edmond
}

Published in:

Chemical Communications

Link to article, DOI:

$10.1039 / \mathrm{d} 0 \mathrm{cc} 07472 \mathrm{a}$

Publication date:

2020

Document Version

Peer reviewed version

Link back to DTU Orbit

Citation (APA):

Xiao, X., Ryan, M. P., Leech, D., Zhang, J., \& Magner, E. (2020). Antimicrobial enzymatic biofuel cells. Chemical Communications, 56, 15589-15592. https://doi.org/10.1039/d0cc07472a

\section{General rights}

Copyright and moral rights for the publications made accessible in the public portal are retained by the authors and/or other copyright owners and it is a condition of accessing publications that users recognise and abide by the legal requirements associated with these rights.

- Users may download and print one copy of any publication from the public portal for the purpose of private study or research.

- You may not further distribute the material or use it for any profit-making activity or commercial gain

- You may freely distribute the URL identifying the publication in the public portal

If you believe that this document breaches copyright please contact us providing details, and we will remove access to the work immediately and investigate your claim 
Cite this paper: Xinxin Xiao, Michael P. Ryan, Dónal Leech, Jingdong Zhang, Edmond Magner;

Antimicrobial enzymatic biofuel cells, Chem. Commun. 2020, DOI: 10.1039/D0CC07472A

\title{
An antimicrobial enzymatic biofuel cell
}

\author{
Xinxin Xiao*,a, Michael P. Ryan ${ }^{b}$, Dónal Leechc, Jingdong Zhang ${ }^{\mathrm{a}}$, Edmond Magner ${ }^{*, b}$ \\ ${ }^{a}$ Department of Chemistry, Technical University of Denmark, Kongens Lyngby 2800, Denmark
}

${ }^{b}$ Department of Chemical Sciences and Bernal Institute, University of Limerick, Limerick, Ireland

'School of Chemistry \& Ryan Institute, National University of Ireland Galway, University Road, Galway, Ireland

Corresponding authors: Xinxin Xiao, E-mail: xixiao@kemi.dtu.dk; Edmond Magner, E-mail: edmond.magner@ul.ie

A compact antibiotic delivery system based on enzymatic biofuel cells was prepared, in which ampicillin was released when discharged in the presence of glucose and $\mathrm{O}_{2}$. The release of ampicillin was effective in inhibiting the growth of bacterium Escherichia coli as confirmed by ex situ and in situ release studies in culture media.



Scheme 1. Schematic illustration of the controlled Amp release using an EBFC.

Microbial infection is the most commonly encountered complication of both medical implants ${ }^{1}$ and of skin wound healing and results in infectious disease associated morbidity and mortality. Antibiotic treatment is the standard therapeutic method for treating these bacterial infections. However, the over and untargeted delivery of antibiotics may lead to antibiotic resistance ${ }^{2}$, highlighting the importance of on-demand controlled release of antibiotics. Precise control of the amount and timing of drug dosage can also prevent toxic side effects ${ }^{3}$. The introduction of antimicrobial delivery systems holds promise for improved delivery and optimal clinical outcomes ${ }^{4}$.

Self-powered drug delivery devices are of interest in triggering localised drug release, eliminating the requirement for external electrical input. For example, Cui et al. fabricated a microrod consisting of a zinc core as the consuming anode and an outer layer comprised of a conductive polymer (CP), poly(3,4-ethylenedioxythiophene) (PEDOT) loaded with the anionic model drug, sulforhodamine $\mathrm{B}^{5}$. The galvanic battery enabled reduction of PEDOT results in expulsion of the incorporated model drug which acts as a counter ion in the oxidised PEDOT layer. In a similar approach, a galvanic cell comprising a zinc anode and a cathode based on another commonly used CP, polypyrrole (PPy) loaded with the anionic dye, phenol red, has been described for self-powered drug delivery. An enzymatic biofuel cell (EBFC) is an electrochemical device utilising immobilised enzymes as catalysts for the conversion of chemical energy in the biofuel into electricity ${ }^{6,7,8}$. Glucose $/ \mathrm{O}_{2}$ and lactate $/ \mathrm{O}_{2}$ EBFCs are promising implantable and wearable power sources, respectively, due to the presence of relatively high concentrations of endogenous glucose in blood (ca. 5 $\mathrm{mM}^{9}$ ) and lactate in tear $\left(2-5 \mathrm{mM}^{10}\right)$ and sweat (20.4 mM under quiescent conditions $\left.{ }^{11}\right)$. In principle, EBFC can avoid the drain issue of zinc in galvanic batteries ${ }^{12}$. Such EBFCs have been demonstrated to be a versatile platform for self-powered drug release ${ }^{12,13,14}$. 
Our recent work described a membrane-less glucose $/ \mathrm{O}_{2}$ EBFC with an additional PEDOT/ibuprofen layer deposited onto an oxygenreducing biocathode ${ }^{12}$. Switchable release of ibuprofen was obtained by opening and closing the circuit in the presence of glucose and dioxygen.
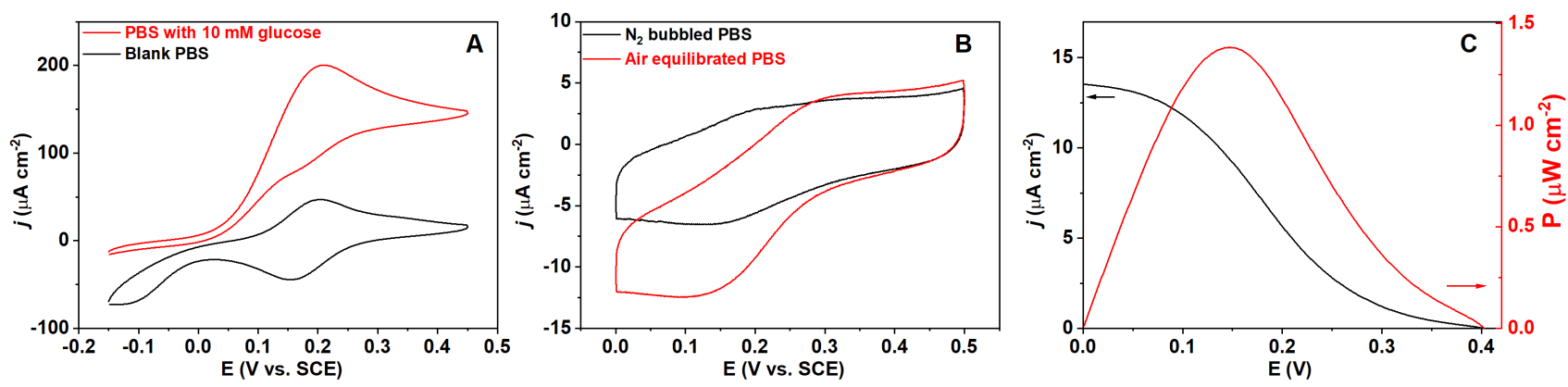

Fig. 1. Cyclic voltammograms of the NPG/Os(bpy) ${ }_{2} \mathrm{PVI}-\mathrm{GOx}$ bioanode (A) and NPG/Os(bpy) ${ }_{2} \mathrm{PVI}-\mathrm{BOx} / \mathrm{PEDOT}-\mathrm{Amp}$ biocathode (B) in $0.1 \mathrm{M}$ pH $7.0 \mathrm{PBS}$ at a scan rate of $5 \mathrm{mV} \mathrm{s}^{-1}$. (C) Power and current density profiles of the EBFC consisting of a NPG/Os(bpy) ${ }_{2}$ PVI-GOx bioanode and a NPG/Os(bpy) ${ }_{2} \mathrm{PVI}-\mathrm{BOx} / \mathrm{PEDOT}-\mathrm{Amp}$ biocathode in air-equilibrated solution containing of $10 \mathrm{mM}$ glucose.

An EBFC with additional antimicrobial function is appealing, in particular for wearable and implantable applications. Herein, we report a one-compartment glucose $/ \mathrm{O}_{2}$ EBFC using enzyme modified nanoporous gold (NPG, thickness $100 \mathrm{~nm}$, pore size ca. $30 \mathrm{~nm}$, roughness factor 7-8) leaf electrodes ${ }^{15}, 16,17$ undergoing mediated electron transfer (MET) (Fig. S1, ESI $)$. [Os(2,2'bipyridine $)_{2}$ (polyvinylimidazole $\left.)_{10} \mathrm{Cl}\right]^{+/ 2+}\left(\mathrm{Os}(\mathrm{bpy})_{2} \mathrm{PVI}\right)$ redox polymer mixed with a poly(ethylene glycol)diglycidyl ether (PEGDGE) crosslinker and either glucose oxidase (GOx) or bilirubin oxidase (BOx), was drop-cast onto NPG as the bioanode and biocathode ${ }^{12}$, respectively (Fig. S2). Subsequently, PEDOT with Amp as an anionic co-dopant (Fig. S1) was electropolymerised on the NPG/Os(bpy) $)_{2}$ PVI-BOx cathode. Amp is a well-studied and widely used potent antibiotic used in the treatment of a spectrum of bacterial infections ${ }^{18}$. Controlled release of Amp was achieved by discharging the EBFC, while paused when the EBFC was opencircuit. The antimicrobial EBFC inhibited the growth of Gram-negative bacterium Escherichia coli when delivering electricity (Scheme 1). Previous reports ${ }^{12,13}$ demonstrated EBFC-enabled controlled release of analgesics and model compounds without showing therapeutic function, in this report, we describe the controlled release of Amp and successfully demonstrate the antimicrobial effect of the released Amp. In contrast, the EBFC exhibited no antimicrobial effect on E. coli at open circuit. To the best of our knowledge, this is the first report on an antimicrobial EBFC. Such devices have the potential to simultaneously generate electricity from physiological fluids and address microbial infection for medical implants and skin wound healing, expanding the scope of EBFC to pharmaceutical applications.

The electrochemical performance of the electrodes was studied separately in three-electrode cells using cyclic voltammetry at a relatively slow scan rate of $5 \mathrm{mV} \mathrm{s}^{-1}$. Fig. $1 \mathrm{~A}$ shows the cyclic voltammograms (CVs) of NPG/Os(bpy) ${ }_{2} \mathrm{PVI}-\mathrm{GOx}$ in $0.1 \mathrm{M} \mathrm{pH} 7.0$ phosphate buffer (PBS). In the absence of glucose (Fig. 1A, black line), a pair of well-defined redox peaks corresponding to the conversion of $\mathrm{Os}^{2+/ 3+}$ was observed, with a peak potential separation $\left(\Delta \mathrm{E}_{\mathrm{p}}\right)$ of $48 \mathrm{mV}$ and a midpoint redox potential $\left(\mathrm{E}_{1 / 2}\right)$ of +180 $\mathrm{mV}$ vs. SCE, very close to the formal redox potential $\left(E^{\circ}\right)^{19}$. This response indicates that $\mathrm{Os}(\mathrm{bpy})_{2} \mathrm{PVI}$ underwent a fast and reversible electron transfer (ET) process on the surface of NPG, as required for an ET mediator ${ }^{6}$. In the presence of 10 mM glucose, a sigmoidal response with negligible cathodic currents (Fig. 1A, red line) was observed, indicative of the catalytic oxidation of glucose. The onset potential for glucose oxidation, obtained by comparing the CVs in the presence and absence of glucose ${ }^{6}$, was ca. $+0.013 \mathrm{~V}$ vs. SCE. The maximum catalytic current density $\left(j_{\max }\right)$, with the contribution from electrode capacitances omitted, was $143.9 \pm 7.5$ $\mu \mathrm{A} \mathrm{cm}{ }^{-2}$ at $+220 \mathrm{mV}$ vs. SCE.

The NPG/Os(bpy) ${ }_{2}$ PVI-BOx/PEDOT-Amp biocathode also exhibited a pair of well-defined redox peaks corresponding to the oxidation and reduction of the $\mathrm{Os}^{2+/ 3+}$ redox couple in $\mathrm{N}_{2}$ bubbled PBS (Fig. 1B, black line). It is notable that the NPG/Os(bpy) ${ }_{2}$ PVIBOX/PEDOT-Amp electrode displayed an increased electrochemical double layer capacitance when compared with the response obtained with NPG/Os(bpy) $)_{2}$ PVI- BOx, an increase arising from the contribution of the pseudocapacitance of PEDOT ${ }^{12,15}$. While 
details of the mechanism are not fully established, such an observation demonstrates that electron transfer (ET) occurs between Os redox polymer and PEDOT layer during operation. As depicted in Scheme 2 (redox potentials and the potential range for PEDOT reduction are taken from literature reports ${ }^{20,21}$ ), the potential range for PEDOT reduction overlaps with the redox potential range of $\mathrm{Os}(\mathrm{bpy})_{2} \mathrm{PVI}$, indicating that ET between the layers is feasible. $\mathrm{A} j_{\max }$ for the oxygen reduction reaction (ORR) of $5.9 \pm 0.2 \mu \mathrm{A} \mathrm{cm}^{-}$ 2 at $+65 \mathrm{mV}$ vs. SCE and an ORR onset potential of $+0.408 \mathrm{~V}$ vs. SCE in air-equilibrated PBS were obtained (Fig. 1B, red line). The $j_{\mathrm{max}}$ of NPG/Os(bpy) $)_{2}$ PVI-BOx/PEDOT-Amp was lower than that of NPG/Os(bpy) ${ }_{2}$ PVI-BOx without a PEDOT layer $\left(50.8 \pm 4.9 \mu \mathrm{Am} \mathrm{cm}^{-2}, \mathrm{Fig}\right.$. S3B), which is likely due to the presence of the second PEDOT-Amp layer acting as an additional diffusion barrier for the supply of $\mathrm{O}_{2}{ }^{12}$. The presence of Amp showed no discernible inhibition of the activity of either GOx or of BOx, as the addition of $0.2 \mathrm{mM}$ Amp in solution did not alter the response (Fig. S3). Fourier transform infrared (FTIR) analysis of the two polymer layers on a gold foil substrate showed the appearance of peaks at 1766 and $1605 \mathrm{~cm}^{-1}$, assigned to the $\mathrm{C}=\mathrm{O}$ stretch vibration ${ }^{22}$ of Amp and the C-C stretch of the thiophene ring of PEDOT $^{23}$, respectively (Fig. S4). Scanning electron microscopy (SEM) shows the randomly distributed porous structure of NPG, with an average pore size of $30 \mathrm{mM}$ along with the coating layers formed on the pore walls (Fig. S5 A-C). Transmission electron microscopy (TEM) confirmed the formation of the polymer layers on NPG skeleton (Fig. S5 DF). The film thickness of the coating layer Os(bpy) ${ }_{2}$ PVI-BOx/PEDOT-Amp was $7.8 \pm 1.2 \mathrm{~nm}$ (Fig. S5F), larger than that of Os(bpy) ${ }_{2} \mathrm{PVI}-$ BOx $(3.0 \pm 0.8 \mathrm{~nm}$, Fig. S5E). No clear boundary between the two polymer layers was observed and some pores of NPG were likely blocked due to the formation of the outer PEDOT-Amp layer (Fig. S5F). These observations together confirmed the successful construction of Os(bpy) ${ }_{2}$ PVI-BOx/PEDOT-Amp onto NPG.

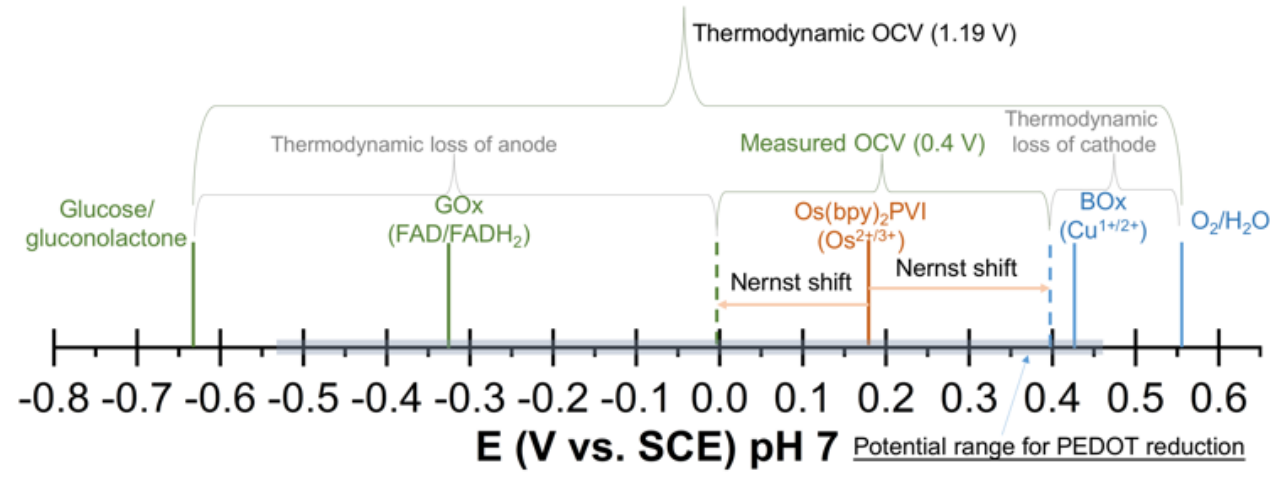

Scheme 2. Potential spectrum in the reactions of the present EBFC and PEDOT.

A membrane-less glucose $/ \mathrm{O}_{2}$ EBFC was subsequently assembled using the NPG/Os(bpy) ${ }_{2}$ PVI-GOx bioanode and NPG/Os(bpy) ${ }_{2}$ PVI-BOx/PEDOT-Amp biocathode (Scheme 1), with the performance of the EBFC evaluated by linear sweep voltammetry (LSV) at a scan rate of $1 \mathrm{mV} \mathrm{s}^{-16}$. In order to achieve as high an open circuit voltage (OCV) of the EBFC as possible with relatively small loss of potential at the bioanode and biocathode (Fig. S6), respectively $6,20,24$, it is normally necessary to employ two different redox mediators with different $\mathrm{E}^{\circ}$ values that are close to those of redox centres of GOx and BOx. However, it is still possible to obtain a reasonable OCV using the same mediator at the bioanode and biocathode ${ }^{12,25,26}$. This is possible as the bioelectrochemical reactions on both electrodes result in different concentration ratios of $\mathrm{Os}^{2+/ 3+}$ at the bioelectrodes, resulting in a Nernstian potential difference from Eo ${ }^{20}$. In practice, the measured OCV is determined by the difference between the onset potentials of the biocathode and bioanode ${ }^{6}$ (Scheme 2). In this case, the EBFC displayed an OCV of $0.403 \mathrm{~V}$, a maximum current density of $13.5 \mu \mathrm{A} \mathrm{cm}^{-2}$, and a maximum power density $\left(P_{\max }\right)$ of $1.38 \mu \mathrm{W} \mathrm{cm} \mathrm{cm}^{-2}$ at $0.146 \mathrm{~V}$ in air-equilibrated PBS with $10 \mathrm{mM}$ glucose (Fig. 1C). As depicted in Scheme 2 and Fig. S6, there is potential to improve the practical OCV of a glucose/ $\mathrm{O}_{2}$ EBFC by adjusting the
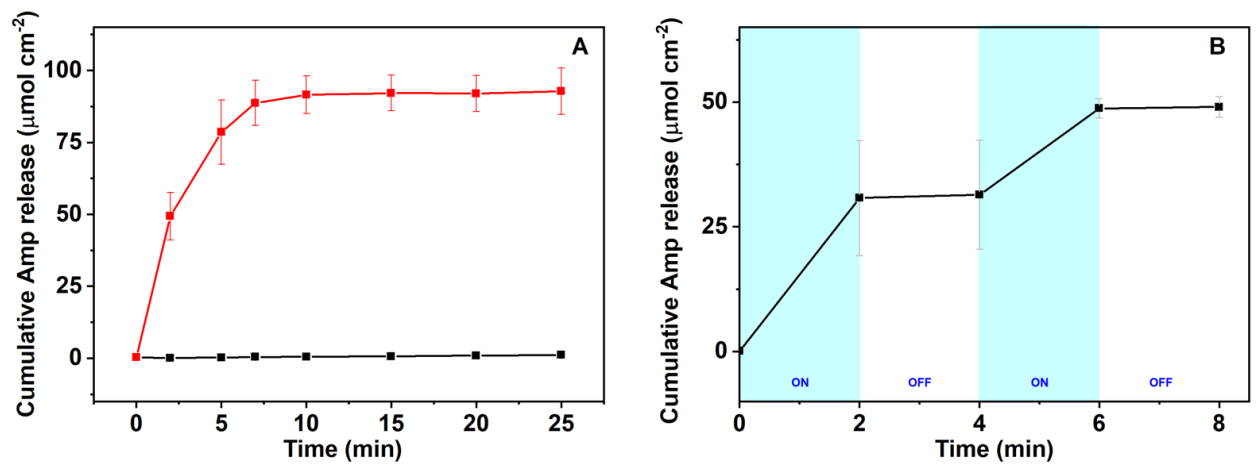

Fig. 2. (A) Cumulative amount of Amp released during the EBFC working at $0.15 \mathrm{~V}$ (red line) and at open-circuit mode (spontaneous release) (black line); solution: air-equilibrated $0.1 \mathrm{M} \mathrm{pH} 7.0$ PBS containing $10 \mathrm{mM}$ glucose. (B) Cumulative amount of Amp released during the EBFC working at an "on-off" sequence: "on" indicates the EBFC working at $0.15 \mathrm{~V}$; "off" indicates the EBFC working at open-circuit mode (blue line); solution: air-equilibrated $0.1 \mathrm{M}$ pH 7.0 PBS containing $10 \mathrm{mM}$ glucose. 
potential of the redox mediator ${ }^{27}$ to approach the thermodynamic value of $1.19 \mathrm{~V}$ for the two-electron oxidation of glucose under standard conditions ${ }^{6}$.

The controlled release of Amp by the EBFC was evaluated. In our previous work ${ }^{12}$, the voltage of the EBFC for the optimal rate of release of drug was equivalent to that for $\mathrm{P}_{\max }$. A potential of $0.15 \mathrm{~V}$ was therefore used for discharge of the EBFC and the cumulative amount of Amp released was determined from the absorbance at $254 \mathrm{~nm}$ (Fig. S7). The rate of release of Amp was approximately linear for the initial $5 \mathrm{~min}$ approaching a maximum value of $92.8 \pm 8.1 \mu \mathrm{mol} \mathrm{cm}^{-2}$ after $10 \mathrm{~min}$ (Fig. $2 \mathrm{~A}$, red line). By comparison, soaking the EBFC in PBS at open-circuit mode led to negligible levels of release of Amp $\left(1.1 \pm 0.1 \mu \mathrm{mol} \mathrm{cm}^{-2}\right.$ after 25 min (Fig. 2A, black line)) that is associated with spontaneous release due to loosely bound Amp. The very low level of spontaneous release clearly demonstrates that discharge of the EBFC with concomitant ET/charge transfer processes is essential for the controlled release of Amp. When the EBFC operated in an "on-off" sequence with alternating discharge at $0.15 \mathrm{~V}$ for $2 \mathrm{~min}$ and standby operation at open-circuit potential for $2 \mathrm{~min}$, rapid release of Amp was observed during the on stages while minimal release during the off stages (Fig. 2B). Such results indicate the feasibility of EBFC enabled controlled Amp release. In an additional control experiment utilising an EBFC with NPG/Os(bpy) ${ }_{2}$ PVI/PEDOT-Amp without BOx as the biocathode, a stable voltage/current output was not obtained with no release of Amp (Fig. S8).
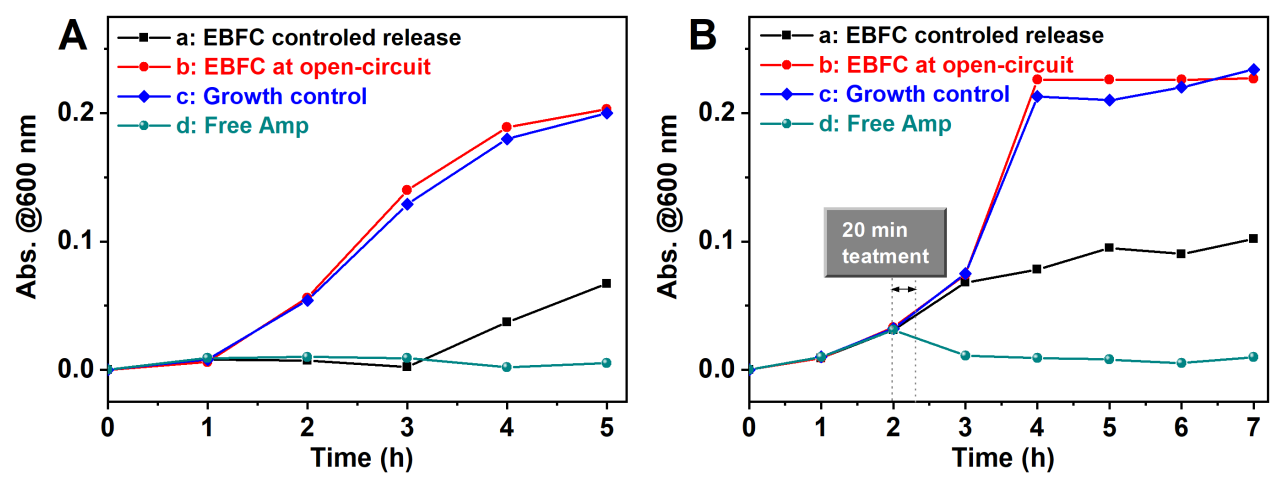

Fig. 3. Optical density at $600 \mathrm{~nm}\left(\mathrm{OD}_{600}\right)$ of $\mathrm{LB}$ broth (measure of antibacterial growth): (A) ex situ release; (B) in situ release. Growth observed with a) EBFC enabled ex situ release of Amp; b): EBFC operating at open-circuit; c): absence of EBFC; d): manual addition of Amp (1 mg mL-1) at time zero.

Release (ex situ and in situ) of Amp was performed to demonstrate the antimicrobial properties of the EBFC, with the antimicrobial efficacy evaluated by monitoring $\mathrm{OD}_{600}$ of Gram-negative $E$. coli sub-cultures over 5-7 h (Fig. 3). E. coli has been widely used as a model bacterium for antimicrobial testing 28,29 , as $E$. coli is among the most common bacterial isolates from serious clinical infections ${ }^{30}$. The prepared EBFC was able to operate in a Luria Bertani (LB) broth, the culture media containing ca. $92.5 \mathrm{mM}$ glucose for $E$. coli propagation and as the biofuel. The EBFC registered an OCV of $0.412 \mathrm{~V}$ and a $\mathrm{P}_{\max }$ of $1.3 \mu \mathrm{W} \mathrm{cm}^{-2}$ at $0.14 \mathrm{~V}$ (Fig. S9), values similar to those obtained in PBS. Ex situ release of Amp at $0.15 \mathrm{~V}$ for 20 min was performed in LB broth, which was subsequently used as the medium for the growth of sub-cultured (1:100) E. coli (Fig. 3A, a). No growth of E. coli occurred in the initial $3 \mathrm{~h}$, after which there was a slight increase in $\mathrm{OD}_{600}$ (Fig. 3A, a). By comparison, when the EBFC was operating at open-circuit, the $\mathrm{OD}_{600}$ increased linearly (Fig. 3A, b), similar to the response without treatment (Fig. 3A, c: blank broth). The presence of Amp (1 mg mL$\left.{ }^{1}\right)$ inhibited the growth of $E$. coli over a period of $5 \mathrm{~h}$ with $O D_{600}$ remaining at zero (Fig. $3 \mathrm{~A}, \mathrm{~d}$ ). The antimicrobial activity observed with the EBFC operating at $0.15 \mathrm{~V}$ (Fig. 3A, a) together with the absence of antimicrobial activity at open circuit potential (Fig. 3A, b) leads to the conclusion that the antimicrobial ability of the EBFC was solely due to the controlled release of Amp and not to any other components of the EBFC.

Sub-cultured (1:100) E. coli was allowed to grow in LB broth for $2 \mathrm{~h}$, showing increased $\mathrm{OD}_{600}$ reading (Fig. 3B). In situ release of Amp in glucose-containing LB broth was then conducted by discharging the EBFC at $0.15 \mathrm{~V}$ for $20 \mathrm{~min}$ (Fig. 3B, a). Additional replication of the bacteria was halted with the $O_{600}$ reading remaining relatively level for another $4 \mathrm{~h}$ (Fig. 3B, a). When the EBFC was operated at open-circuit potential (Fig. 3B, b) and in a control experiment with no addition of Amp (Fig. 3B, c), the OD 600


with $\mathrm{OD}_{600}$ decreasing close to 0 (Fig. $3 \mathrm{~B}, \mathrm{~d}$ ). Consumption of glucose by the bacteria and EBFC is not likely to be the origin of the observed antimicrobial effect. The concentration of glucose (ca. $92.5 \mathrm{mM})$ in the media will not change significantly $(<100 \mu \mathrm{M}$ for a constant current of $20 \mu \mathrm{A}$ ) during the $20 \mathrm{~min}$ of operation of the EBFC. As evident from Fig. 3B, bacterial growth continues at the same rate for the control (Fig. 3B, c) and when the EBFC is at open circuit (Fig. 3B, b), demonstrating that the supply of all nutrients is sufficient. Overall, such control studies demonstrated the controlled antimicrobial performance of the EBFC with controlled release of Amp by switching "on" and "off" the circuit.

In conclusion, a membrane-less glucose $/ \mathrm{O}_{2}$ enzymatic biofuel cell (EBFC) has been described with antimicrobial properties arising from the release of ampicillin that is triggered by discharging the EBFC. The EBFC demonstrated an antimicrobial effect towards E. coli. The EBFC has the potential to be applied as antimicrobial surfaces for a wide range of clinical purposes such as implant coatings and treating skin wound infections. It is envisioned that a rationalization of mediator potential and bilayer 
configuration could further improve the efficiency of the antibiotic release system. A further combination of the antimicrobial EBFC with a diagnostic unit would achieve an appealing "sense-act-treat" platform.

Financial support from The Danish Council for Independent Research for the YDUN project (DFF 4093-00297), Villum Experiment (grant No. 35844) and ImplantSens (project no. 813006) is gratefully acknowledged. Dr. Peter Ó Conghaile is acknowledged for synthesising the Os polymer.

\section{Conflicts of interest}

There are no conflicts to declare.

\section{Notes and references}

1 C. Mas-Moruno, B. Su and M. J. Dalby, Adv. Healthc. Mater., 2019, 8, 1801103.

2 K. P. Miller, L. Wang, B. C. Benicewicz and A. W. Decho, Chem. Soc. Rev., 2015, 44, 7787-7807.

3 S. E. Birk, J. A. J. Haagensen, H. K. Johansen, S. Molin, L. H. Nielsen and A. Boisen, Adv. Healthc. Mater., 2020, 9, 1901779.

4 Y. Liu, L. Shi, L. Su, H. C. van der Mei, P. C. Jutte, Y. Ren and H. J. Busscher, Chem. Soc. Rev., 2019, 48, 428-446.

5 Q. Cui, T.-H. Le, Y.-J. Lin, Y.-B. Miao, I. T. Sung, W.-B. Tsai, H.-Y. Chan, Z.-H. Lin and H.-W. Sung, Nano Energy, $2019,66,104120$.

6 X. Xiao, H.-q. Xia, R. Wu, L. Bai, L. Yan, E. Magner, S. Cosnier, E. Lojou, Z. Zhu and A. Liu, Chem. Rev., 2019, 119, 9509-9558.

7 S. Fan, B. Liang, X. Xiao, L. Bai, X. Tang, E. Lojou, S. Cosnier and A. Liu, J. Am. Chem. Soc., 2020.

8 D. Leech, P. Kavanagh and W. Schuhmann, Electrochim. Acta, 2012, 84, 223-234.

9 D. G. Maggs, R. Jacob, F. Rife, R. Lange, P. Leone, M. J. During, W. V. Tamborlane and R. S. Sherwin, J. Clin. Invest., 1995, 96, $370-377$.

10 E. R. Berman, Biochemistry of the Eye, Springer Science \& Business Media, New York, 1991.

11 D. A. Sakharov, M. U. Shkurnikov, M. Y. Vagin, E. I. Yashina, A. A. Karyakin and A. G. Tonevitsky, Bull. Exp. Biol. Med., 2010, $150,83-85$.

12 X. Xiao, K. Denis McGourty and E. Magner, J. Am. Chem. Soc., 2020, 142, 11602-11609.

13 M. Zhou, N. Zhou, F. Kuralay, J. R. Windmiller, S. Parkhomovsky, G. Valdés-Ramírez, E. Katz and J. Wang, Angew. Chem. Int. Ed., 2012, 51, 2686-2689.

14 L. Wang, H. Shao, X. Lu, W. Wang, J.-R. Zhang, R.-B. Song and J.-J. Zhu, Chem. Sci., 2018, 9, 8482-8491.

15 X. Xiao, P. Ó. Conghaile, D. Leech, R. Ludwig and E. Magner, Biosens. Bioelectron., 2017, 90, 96-102.

16 X. Xiao, P. Ó. Conghaile, D. Leech, R. Ludwig and E. Magner, Biosens. Bioelectron., 2017, 98, 421-427.

17 X. Xiao, J. Ulstrup, H. Li, J. Zhang and P. Si, Electrochimica Acta, 2014, 130, 559-567.

18 I. L. Ahrén, E. Karlsson, A. Forsgren and K. Riesbeck, J. Antimicrob. Chemother., 2002, 50, 903-906.

19 M. N. Zafar, F. Tasca, S. Boland, M. Kujawa, I. Patel, C. K. Peterbauer, D. Leech and L. Gorton, Bioelectrochemistry, $2010,80,38-42$.

20 F. Conzuelo, N. Marković, A. Ruff and W. Schuhmann, Angew. Chem. Int. Ed., 2018, 57, 13681-13685.

21 M. Dietrich, J. Heinze, G. Heywang and F. Jonas, J. Electroanal. Chem., 1994, 369, 87-92.

22 S. P. Singh, S. K. Sharma and D. Y. Kim, Solid State Sci., 2020, 99, 106046.

23 B. Mutharani, P. Ranganathan and S.-M. Chen, Sens. Actuators B Chem, 2020, 304, 127361.

24 X. Xiao and E. Magner, Chem. Commun., 2015, 51, 13478-13480.

25 H. Chen, M. B. Prater, R. Cai, F. Dong, H. Chen and S. D. Minteer, J. Am. Chem. Soc., 2020, 142, 4028-4036.

26 D. Pankratov, F. Conzuelo, P. Pinyou, S. Alsaoub, W. Schuhmann and S. Shleev, Angew. Chem. Int. Ed., 2016, 55, 15434-15438.

27 V. Soukharev, N. Mano and A. Heller, J. Am. Chem. Soc., 2004, 126, 8368-8369.

28 V. Sambhy, M. M. MacBride, B. R. Peterson and A. Sen, J. Am. Chem. Soc., 2006, 128, 9798-9808.

29 G. Armstrong, R. Thornton, M. P. Ryan, F. Laffir, R. J. Russell, T. Bala, C. Keely and R. Babu, Polym. Bull., 2012, 68, $1951-1963$.

30 R. N. Jones, Am. J. Med., 1996, 100, 3S-12S. 